\title{
The advantages of mechanised cable bolting in the modern underground mine
}

\author{
K. Winder Macmahon Mining Services, Australia \\ B. Maney Macmahon Mining Services, Australia
}

\begin{abstract}
Cable bolting is rapidly increasing in popularity in underground mines as safety standards are raised and mining environments become more challenging. Traditional hand installation of cables can be time consuming, exposes personnel to unnecessary risks and has the potential for manual handling injuries. Mechanised cable bolting machines are gaining wider acceptance as the safety, efficiency and quality benefits associated with them are being realised by mine operators. This paper discusses the advantages and limitations associated with the use of mechanised cable bolt rigs in underground mines.
\end{abstract}

\section{Introduction}

Mechanised cable bolting machines are purpose built for the drilling of holes, mixing and pumping of grout and installation of cable bolts in underground mines. They enable one operator and one machine to perform a task, which traditionally involves the drilling of holes by one machine and then the installation of grout and cable manually by a crew of two to three using a grout pump.

\section{Cable bolting in development mining}

Cable bolts are increasingly being used to provide support for development openings in mines. In previous years they were generally only used in development where unfavourable rock structure existed or where the dimension of openings in conjunction with the orientation and persistence of structures present meant that a longer and higher capacity rockbolt element was required. Cable bolts were largely used for the support of drive intersections, large caverns and stope walls.

As development is increasingly being pushed into deeper, higher stress and poorer ground conditions, the use of cable bolts in development mining has increased. Some examples include:

- The use of in-cycle, $6 \mathrm{~m}$ long, twin strand cable bolts on $1.25 \mathrm{~m}$ ring spacings in the Progress orebody at BHP Billiton's Perseverance Mine in Western Australia (Tyler and Werner, 2004).

- The use of 7-9 $\mathrm{m}$ long, twin strand, bulb cable bolts on a 2 × $2 \mathrm{~m}$ spacing in the weak, high deformation ground conditions at the Cayeli mine in Turkey (Yumlu and Bawden, 2004).

- The use of yielding (dynamic) cables installed on a $1.8 \mathrm{~m}$ square pattern in deep squeezing ground at the Brunswick mine in Canada (Gaudreau, 2004).

- The installation of single strand, yielding, Garford cables of $6 \mathrm{~m}$ length in development drives where high convergence is anticipated at the Black Swan nickel mine in Western Australia. These cables are installed no more than three cuts behind the development mining face (Potvin and Slade, 2007).

The need for cable bolts to be installed at greater frequencies and in increasing volumes has meant that traditional drilling of cable bolt holes using a development or production drill machine followed by installation by hand is becoming inefficient.

\section{The mechanised cable bolt rig}

There are several purpose built cable bolting rigs available on the market today including the Sandvik DS420 (previously the Cabolt 7-5) and the Atlas Copco Cabletec LC rig which has two booms - a drilling and a 
grouting boom. The Sandvik Cabolt machine has been in operation for the longest and is the most common cable bolting machine found in Australia. The following section will relate primarily to the Sandvik machine.

\subsection{Operation of Sandvik Cabolter}

The mechanised cable bolting machine is designed to be operated by a single person. The machine is purpose built to achieve the drilling of suitable boreholes, the mixing and pumping of grout and the installation of steel cable into the boreholes.

\subsubsection{Machine design}

Mechanised cable bolting rigs combine a drilling boom with the necessary components to facilitate installation of grout and steel cable strands into a drill hole. The Sandvik DS420 machine (Figure 1) is based on a rubber tyred, underground suitable carrier which has many elements in common with underground development and production rigs. It is an electric over hydraulic machine that uses a diesel engine for tramming.

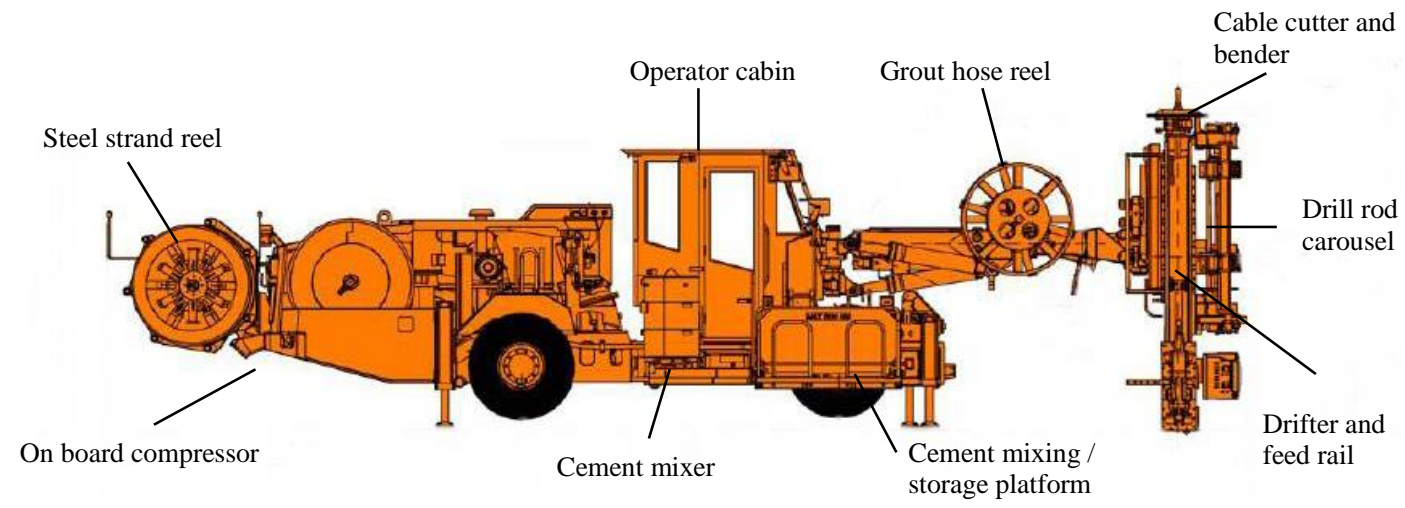

\section{Figure 1 Some basic elements of the Sandvik DS420 mechanised cable bolter (after Sandvik Mining and Construction, 2008)}

Drilling can be facilitated using the onboard compressor if required or the compressed air reticulation system underground. The drilling boom can be rotated through $360^{\circ}$ to allow full ring drilling and can dump forwards to $55^{\circ}$ and backwards to $35^{\circ}$. Drill rods are stored in the rod carousel and can be changed using the pito centraliser to hold rods in the hole while the gripper arm removes or reinstalls rods into the carousel. Drilling accuracy is enhanced through the use of "stinger" stabilisers on each end of the drill boom. A tamrock management system (TMS) control panel is fitted as standard and provides the operator with a full spectrum of operational readings including mast angle inclinations, drill depth, cable depth and grout hose depth measurement.

The grouting and cable installing system consists of a reel at the rear of the carrier to which a cassette of steel cable is fitted. The cable is fed through a plastic tube by the cable feeder box to the head of the boom, from where it can be pushed up the borehole. The cement grout is prepared in a cement mixer mounted on a platform on the side of the machine, which is manually loaded with cement powder. A grout pump pumps the mix through the grout hose which is fed up the hole from the grout hose reel and up through the head of the boom. A cable cutter and bender is located at the head of the boom to bend the cable as it is installed which serves to aid retention of the cable in the hole while the grout hydrates, and to cut the cable when it has been installed to the full design length.

\subsubsection{Installation method}

Cable bolts are installed using the mechanised cable bolting machine by the process shown in Figure 2 . Initially, a borehole is drilled at the design location, angle, diameter and depth. The drill rods are then retracted from the hole. Usually a series of holes are drilled before installing starts and if circumstances permit at least enough holes to be filled with one batch of cement grout are drilled. 
The cement mixer is then loaded with water and powdered cement at the correct ratio for the holes being grouted. Typically for upholes a water to cement ratio of 0.3:0.35 will be used and for downholes a ratio of 0.35:0.4 will be used. A dosage meter is located on the water inlet to the cement mixer so that the correct ratio can be achieved for the number of cement bags added.

After the grout has been adequately mixed, the grout pump is run with the grout hose pointing to the ground to enable the discharge of any water in the lines and a small amount of the grout. The grout pump can then be stopped and the boom manoeuvred so that the grout hose can be extended into the drill hole until it hits the end of the hole. The operator then turns the grout pump on to fill the end of the hole and then slowly starts to retract the hose, occasionally pausing to check that the hole is being filled continuously and no air voids are being formed.

When the hole has been slightly overfilled, the grout pump is stopped and the grout hose is retracted. The steel cable strand is then fed through the plastic guide tube and into the grout column in the drill hole. Just before the strand reaches the end of the hole a kink is put into it by the cable bender at the head of the boom. When the strand has been installed to full depth the cable strand is cut using the cable cutter located at the head of the boom. A second strand can then be installed alongside the first if required.

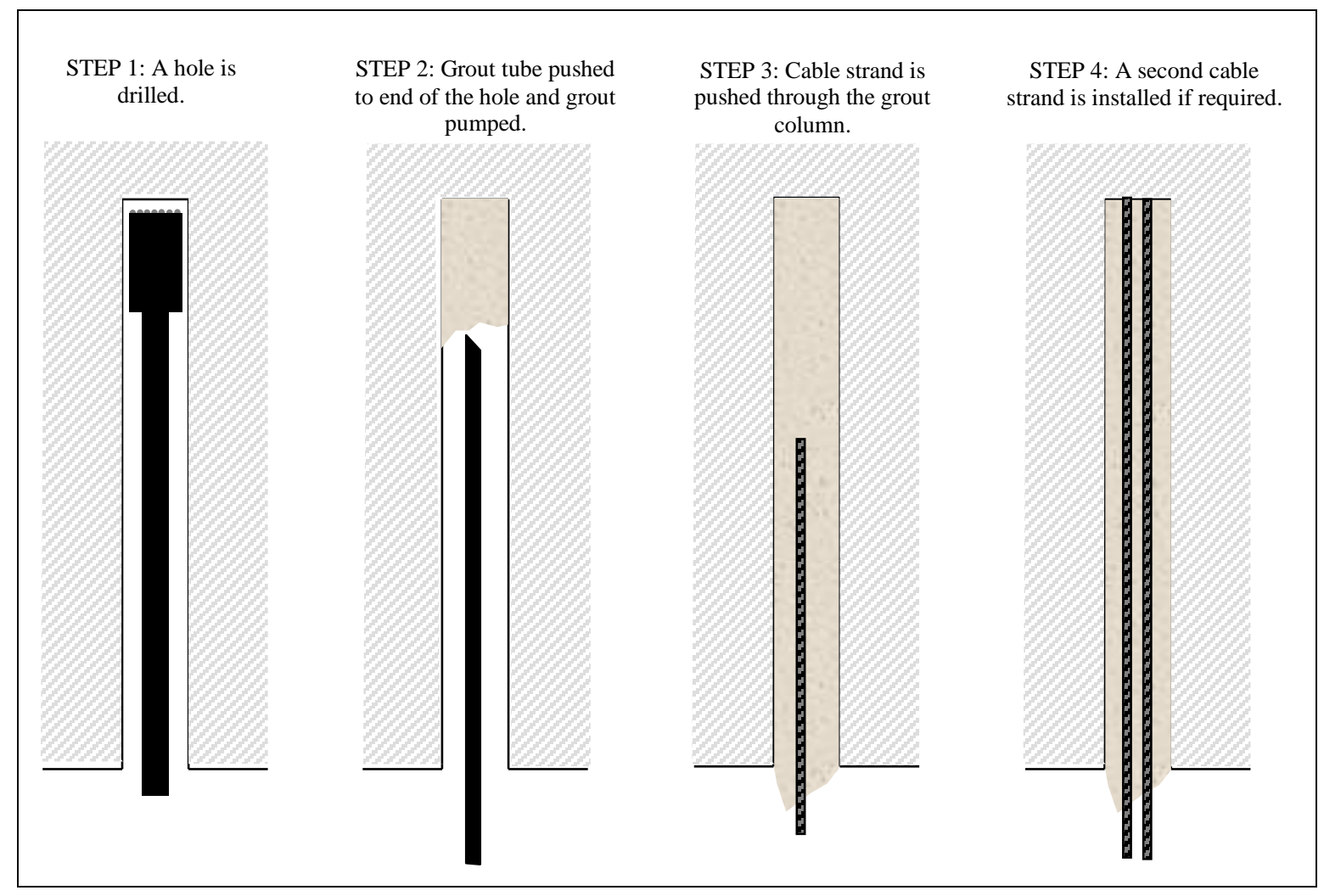

Figure 2 Process of installing cable strands using the mechanised cable bolting rig

\subsubsection{Capability}

Mechanised cable bolting machines are typically capable of drilling and installing cable bolts up to $25 \mathrm{~m}$ in length. The drill string is usually composed of R32 to T38 sized equipment enabling hole sizes from $51 \mathrm{~mm}$ to $64 \mathrm{~mm}$ to be drilled.

Both plain strand and some modified geometry seven wire cables at a diameter of $15.2 \mathrm{~mm}$ can be installed using the mechanised cable bolting machine. Modified geometry cables used are typically "mini bulb" types with bulb diameters of up to $25 \mathrm{~mm}$.

Fixed length, dynamic type cables have also been successfully installed using the cable bolting rig. A dynamic cable bolt refers to a cable where a portion of the bolt length is encased in a plastic tube so that it is not in contact with the grout and can stretch along this length in response to ground movement. 


\subsection{Advantages}

The advantages of using a mechanised cable bolting machine to install cables over traditional methods such as drilling with a development or production drill machine followed by hand installation of cables can be considered in terms of safety, efficiency and quality.

\subsubsection{Safety}

Installation of cable bolts in upholes by hand requires personnel to stand in close proximity to the ground being supported which has usually been recently disturbed through drilling. The drilling process can result in loose rock or scats being present in mesh which presents a hazard if they are not identified and removed prior to work in the area. In addition to this, during hand grouting of cables there is the potential for grout to be dislodged from the hole under pressure and into the face of the operator. The installed cable bolts can also become a hazard to workers below if they become dislodged from the hole while the grout is still wet. With the use of a mechanised cable bolting machine, the operator is within the operator's cabin and well removed from this potential hazard whilst drilling and installing cables.

For expediency, boreholes for cable bolts in development headings are often drilled using a development drill. These machines are generally not equipped for drilling holes in excess of 3-4 $\mathrm{m}$ in length as this is all that is typically required for face advance. Jaws can be installed on these drills to enable one rod to be held up in a hole while the shank is decoupled and retracted so that a second rod can be added. With the boom in this position, an operator has to stand very close to the rod being held up in the hole by the jaws to load the second rod, thus exposing themself to the potential hazard of the rod being dislodged. On development drill rigs where jaws are not installed, drilling cable holes at greater lengths than the drill steel is done using some questionable methods.

Manual handling is also reduced with the use of a mechanised cable bolting machine. Pushing cables manually into upholes can be an arduous task, as can changing drill rods manually. The use of a mechanised cable bolter removes the need to do either. Manual handling of cement bags into the cement mixer is still required; however some new prototype cable bolting machines have been designed with on board cement storage which is discharged into the cement mixer mechanically.

Exposure to cement grout is also reduced with the use of a cable bolting machine. The operator does not have to handle the end of the hose from which the grout is being pumped or stand below a hole collar into which grout is being pumped. This can greatly reduce the incidence of eye and skin irritations that are due to contact with cement.

\subsubsection{Efficiency}

Mechanised cable bolting can achieve far higher installation rates than hand installation of cables. Hutchinson and Diedrichs (1996) present data collected by Goris et al. detailing production rates achieved for cable insertion and grouting from three Canadian mines. Considering the data from one of these mines that employs a 12 hour shift shows that cable insertion of $166 \mathrm{~m}$ a shift and grouting at a rate of $230 \mathrm{~m}$ a shift is achieved. This means that on average $195 \mathrm{~m}$ of installed cable can be achieved each shift with a three person crew. This does not include the time required for the drilling of these holes (which is generally double the time installing takes). Taking this into account, the achievable rate for drilling and installing would be approximately $65 \mathrm{~m}$ per shift. A cable bolting machine can achieve on average the drilling and installation of $5500 \mathrm{~m}$ a month which equates to $92 \mathrm{~m}$ per shift with only a one person crew.

Installation rates in excess of $5500 \mathrm{~m}$ per month have also been achieved. Figure 3 shows data from an Australian mine using a cable bolting machine over a twelve month period. The average installation rate per month is $6340 \mathrm{~m}$, which equates to $106 \mathrm{~m}$ per shift. 


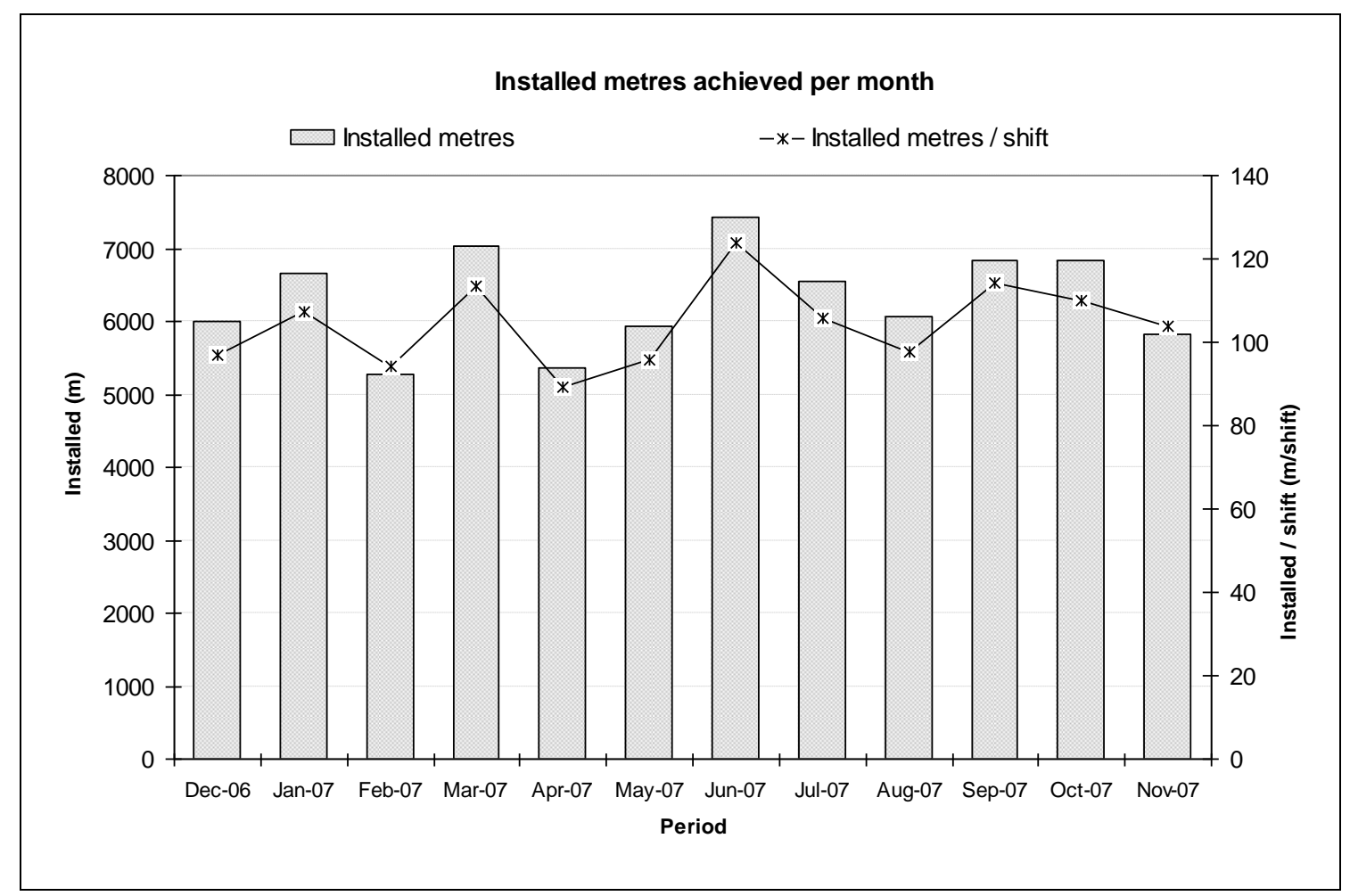

Figure 3 Cable bolt installation rates achieved with a mechanised cable bolting machine

The increased rate of installation, combined with the fact that drilling, installing and grouting functions are performed by the one machine operated by one person mean that mechanised cable bolting has significant advantages for the rapid advancement of drives where in-cycle cable bolting is required.

\subsubsection{Quality}

In several respects, the quality of a cable bolt installation with a cable bolting machine can be superior to that of a hand installed bolt. Hand installation is performed through two main methods: the breather tube method or the grout tube method. The breather tube method is generally used where a less viscous grout is employed either to enable full encapsulation of modified cable bolt geometries or due to limitations in grout pumping equipment. The grout tube method can be applied where a thicker grout is used and involves either a grout tube being taped to the cable, installed in the hole and grout pumped in until it fills the hole; or a grout tube being retracted from the hole as grout is pumped in. Where the grout tube is taped to the cable, the collar of the hole is usually blocked off using a wooden wedge to prevent grout being ejected from the hole.

Poorer quality installation can result from using the breather tube method due to the higher water:cement ratio grout that is often used. The strength of any cement grout will reduce with the increase in water content due to the excess water forming micro air voids within the grout matrix, thus weakening it. There is a tendency towards using higher water:cement ratio grouts with the breather tube method as the hole is blocked so there is no requirement for the grout column to be self supporting in the uphole and a higher water:cement ratio makes the mix easier to pump into the hole. If the breather tube is not adequately blocked while pumping is still occurring, it can also result in an air void in the breather tube running alongside the cable.

Installation using the grout tube method and a more viscous grout is generally on par with that achieved using a mechanised cable bolter, though if the grout tube is left in place in the hole it may prevent complete encapsulation of the cable strand in cement. The lower water:cement ratios used in the grout tube hand installation method and with the use of a mechanised cable bolter mean that grout strength is typically high.

Additional factors that improve quality of installation with a cable bolting machine include the use of metering and measuring devices on the machine. These include: TMS, for hole depth indicators, hole position and length accuracy, water metering into the cement mixture to achieve correct water:cement ratios 
and counters which measure the length of grout tube and cable bolt up the hole. As the operator also has the benefit of drilling all of the holes in an area and then installing into them, experience of the ground conditions is gathered first hand which can assist in improving installation quality.

\subsection{Limitations}

There are some limitations to the use of a cable bolting machine. These are primarily associated with the fact that the hole collar cannot be plugged and the geometry of the cable that can be installed is limited by the feeder box capability.

\subsubsection{Wet holes}

Wet holes are always a problem for the installation of cement grouted bolts, no matter what method may be employed. The water usually flows through fissures and joints in the ground, so even if the hole collar can be plugged, cement particles can still be carried away through the ground by the water flow, negatively affecting the water:cement ratio. When using a mechanised cable bolter to install cables the collar of the hole cannot be plugged. This means that in wet ground it is likely that more of the grout column will be displaced by water.

When using a mechanised cable bolt rig to install cables in wet ground, an operator will typically make a mix of cement grout with a very low water:cement ratio in an attempt to stop the grout slumping out of the hole. Where water:cement ratios are lower than 0.3 , there will be inadequate water to properly mix the grout, resulting in lumps of cement which will not be hydrated. This will result in some portions of the grout column that are weaker than others. In addition to this there will be portions of the hole where water has washed away the grout column into fissures and as the hole collar cannot be plugged there may be portions of the grout column that are pushed out of the hole due to water pressure.

There is no simple way to overcome the problems associated with installing cable bolts in wet ground, but hand installation may offer some advantages to the quality of the installation such as:

- Plugging the collar of the hole is possible to prevent slump of the grout column through water pressure.

- Plugging the collar of the hole will also allow grout to be pumped into the hole under pressure, enabling it to fill some of the cracks and fissures that may be present in the walls of the hole. If the cracks are narrow, this may be successful in halting water flow.

- Efforts can be made to plug other water bearing fissures that daylight in the excavation adjacent to the boreholes, which may assist in the grout being retained within the rock mass.

Engineers involved with the design and supervision of cable bolting activities should consider the various advantages and disadvantages of methods of cable bolt installation where wet conditions are encountered.

\subsubsection{Hole length and diameter}

The maximum achievable hole length that cable can be pushed up using a mechanised cable bolt rig is $25 \mathrm{~m}$. This is mainly due to the achievable feed box pressure and the resistance involved with pushing the cable strands through the grout.

Minimum hole diameter is limited to $51 \mathrm{~mm}$ for a modified geometry cable to ensure adequate grout surrounding the bulbs. The larger the hole, generally the more accurately it can be drilled, so a $51 \mathrm{~mm}$ hole is also optimal from this perspective. Maximum hole diameter is generally limited to $57 \mathrm{~mm}$ for an uphole. In a $64 \mathrm{~mm}$ uphole the combined weight of the cable and grout column and the fact that the collar is unplugged can lead to slump of the grout. If cables are being countersunk (that is a portion of the cable is to be left ungrouted), the possibility of undetected grout slump in the hole should be considered if using a larger diameter hole. 


\subsubsection{Modified geometry bolts and encapsulation}

The geometry of cable bolts that can currently be installed using the cable bolt rig are limited by the capabilities of the cable feeder box. The current configuration of the feeder box enables a standard $15.2 \mathrm{~mm}$ diameter cable strand to be used.

A mini bulb type cable is often used where additional anchorage is required. The bulbs are usually formed to a maximum diameter of $25-28 \mathrm{~mm}$ and are compressed slightly by the feeder box pressure (Figure $4 \mathrm{a}$ ). This is unavoidable as the feeder box must apply a certain pressure to the perimeter of the cable strand to enable it to push the cable up into a vertical hole, however care must be taken that the pressure doesn't cause the bulbs to be compressed to any less than $23 \mathrm{~mm}$ in diameter. It is possible that the use of a ferruled or nutcaged type of strand where the bulb has a solid core would alleviate this problem, though the cost of this type of cable is usually prohibitive.

Using a mechanised cable bolt machine, it is possible to pump lower water:cement ratios than is optimal ( 0.3 or less). This can lead to other problems associated with the cable geometry such as insufficient grout penetration into bulbs and poor encapsulation when a cable is dislodged or moved within a hole and the grout cannot flow back around it (Figures $4 \mathrm{~b}$ and $4 \mathrm{c}$ ). As the cables are installed after the grout column is established, there are several possible sources for movement of the cable which can cause grout to be dislodged such as: kinking of the cable strand as it is inserted, cutting of the cable strand and installation of a second cable strand which interacts with the first. If the water:cement ratio is too low, the grout is not sufficiently fluid to refill the voids around the cable and poor encapsulation will result. Care must be taken to educate operators in the implications of using a low water:cement ratio grout so that these issues are avoided.

Installation of the cable strands with the mechanised cable bolting rig also precludes the use of devices such as spacers and centralises which can be used in hand installation to obtain better positioning of the cable within the hole (Figure 4d). This can result in cable strands located too close to one another within the hole and the strands being pushed up against the sidewall of the hole.

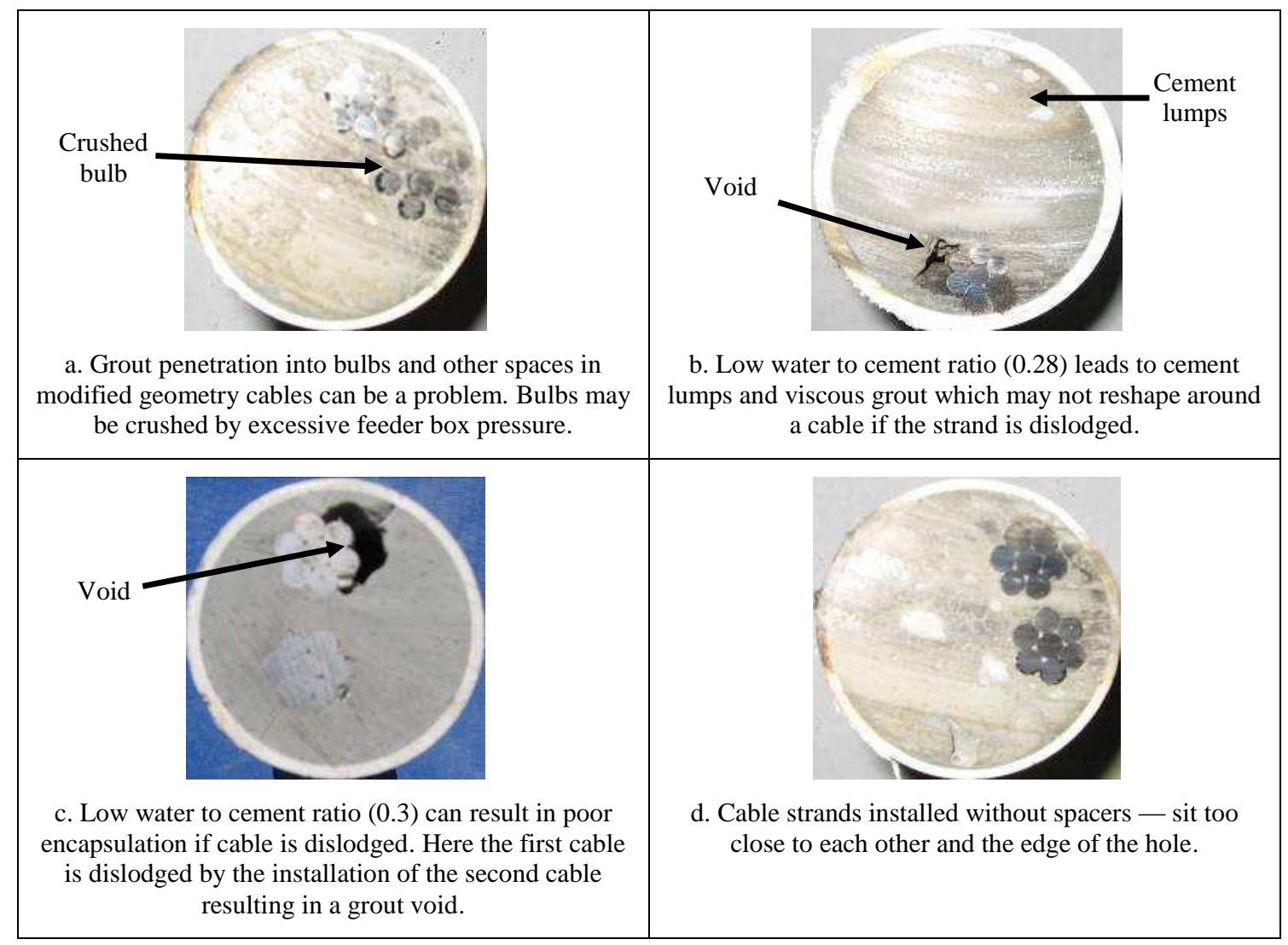

Figure 4 Various quality issues that may occur in cable bolt installation 


\section{Conclusion}

The use of mechanised cable bolt machines offers advantages to modern mining in terms of safety, efficiency and quality. With the increasing need in the underground mining industry to support development drives with cable bolts as they are advanced, the use of mechanised cable bolting can contribute both to reducing cycle times and increasing safety for mine workers. There are several limitations that need to be considered by the design engineer, and careful consideration should be made when employing the machines in areas where the ground is wet, large hole diameters are used for upholes and modified geometry bolts are required.

\section{References}

Gaudreau, D. (2004) A Ground support practices at Brunswick Mine, NB, Canada, Proceedings of the Fifth International Symposium on Ground Support in Mining and Underground Construction, E. Villaescusa and Y. Potvin (eds), September 2004, Perth, Australia, A.A. Balkema, The Netherlands, pp. 53-63.

Hutchinson, D.J. and Diedrichs, M.S. (1996) Cablebolting in Underground Mines, BiTech Publishers, British Columbia, p. 20.

Potvin, Y. and Slade, N. (2007) Controlling extreme ground deformation — Learning from four Australian case studies, Challenges in Deep and High Stress Mining, Y. Potvin, J. Hadjigeorgiou and R. Stacey (eds), Australian Centre for Geomechanics, Perth, Australia, pp. 355-361.

Sandvik Mining and Construction (2008) Technical Specifications Sandvik DS420, viewed on 12/12/2008, http://www.miningandconstruction.sandvik.com/sandvik/1281/Internet/MANorway/SE03605.NSF/Alldocs/Prod ucts*5CDrill*rigs*and*rock*drills*5CUnderground*drill*rigs*5CRock*support*drill*rigs*2ADS420/\$FILE/D S420_84300f.pdf

Tyler, D.B. and Werner, M. (2004) A case study of ground support improvement at Perseverance Mine, Proceedings of the Fifth International Symposium on Ground Support in Mining and Underground Construction, E. Villaescusa and Y. Potvin (eds), September 2004, Perth, Australia, A.A. Balkema, The Netherlands, pp. 53-63.

Yumlu, M. and Bawden, W.F. (2004) An integrated ground support design in very weak ground at Cayeli Mine, Proceedings of the Fifth International Symposium on Ground Support in Mining and Underground Construction, E. Villaescusa and Y. Potvin (eds), September 2004, Perth, Australia, A.A. Balkema, The Netherlands, pp. 97-111. 